\section{Facet joint injection in lower back pain-is its continued use justified?}

The injection of local anaesthetic and/or steroids into the facet joint is being practiced widely throughout the NHS and worldwide as a means of treating patients in whom it is believed the facet joint is the cause of the symptoms of their back pain. However, the effectiveness of this therapy for short- and long-term pain relief requires evaluation, as this has far reaching financial and social consequences.

Ghormley' originally used the phrase 'facet joint syndrome' to depict back pain caused by pathology at the facet joints. Intra-articular facet injections of hypertonic saline and subsequent pain reproduction were performed by Hirsch $^{2}$ in 1963 and by Mooney and Robertson ${ }^{3}$ in 1976 supporting the role of facet joints in lower back pain.

It is important to note that the facet joints have a richly innervated capsule and the medial branches of the posterior lumbar rami (themselves branches of the lumbar spinal nerves) provide this innervation. In addition, the joints have been shown to hold up to a maximum of $1-2 \mathrm{~mL}$ of injected fluid by anatomical studies. Above this level, rupture of the joint capsule occurs and a resultant extravasation into the back and epidural space leade to non-specific therapeutic effects. ${ }^{4-6}$

Lower back pain which originates from the facet joints has not been shown by studies to relate to radiological or pathological changes. ${ }^{7-10}$ The value of plain radiographs, computed tomography and magnetic resonance imaging scans in diagnosing facet joint disease remains inconclusive: degenerative facet joint changes may be seen in asymptomatic patients, and the converse is also true. ${ }^{7-10}$ Bone scintigraphy with single photon emission computed tomography (SPECT) is more sensitive in detecting facet joint lesions and allows more accurate anatomical localization. A recent study suggested that SPECT could help to identify patients with low back pain who would benefit from facet joint injections. ${ }^{11}$

The advocates of the continuing use of facet joint injections suggest that pain relief in patients following the injection is a diagnostic tool for confirmation of facet joint pathology. ${ }^{9,12}$ However, others insist that both a positive pain provocation response and pain relief are necessary as diagnostic criteria. ${ }^{9}, 10$ Furthermore, there is little evidence in any of the available literature that arthrogram is undertaken for confirmation of the correct placement of the needle into the facet joint. Care needs to be taken in order to limit the amount of contrast injected - bearing in mind the facet joint can only hold up to $1-2 \mathrm{~mL}$ and that the steroid or local anaesthetic must subsequently be introduced.

More objective assessment of facet joint injections is lacking. In a study by Holm et al. ${ }^{13}$ an attempt was made to determine an objective and reliable measurement of the effectiveness of facet joint injections. The authors postulated that because the best responders to facet joint injections had the most pain on extension after forward flexion in the standing position, then, after pain relief, an expected measurable progress in muscle strength would be observed. Unfortunately, no influence on isokinetic muscle performance was found. An objective measurement of the effectiveness of facet joint injections remains elusive.

It can be argued that studies assessing the long-term effects of facet joint injections do not take into account confounding variables. Perhaps facet joint injections simply offer a window of pain relief during which more rigorous physiotherapy and other treatment modalities can be instituted? Thus, good long-term results obtained in some studies do not take into account other treatment modalities taken by patients (e.g. alternative medications, physiotherapy and exercise). In addition, the natural history of the facet joint pain diminishing with time needs to be considered when reviewing the results of long-term follow-up studies.

Two recent publications by Slipman ${ }^{14}$ and van Tulder ${ }^{15}$ performed critical analysis of all available literature and found that these injections were not clearly shown to be effective and hence cannot be recommended. These studies reviewed current evidence using the results of systematic reviews within the Cochrane database. This adds further weight to our argument that there is insufficient evidence in support of facet injections. ${ }^{14,15}$ A systematic review by Boswell et al. ${ }^{16}$ suggested that there is moderate evidence (level 3) of an improvement in symptoms following facet injection. Of the studies reviewed by the authors, only Carette et al. ${ }^{17}$ performed a double blind, randomized placebo-controlled trial, and this in fact found no short- or long term improvement. In addition, no studies were performed which evaluated cost-effectiveness of therapeutic intra-articular facet joint injections.

We suggest that further well-designed, prospective, double-blind, randomized, controlled trials are required to evaluate the therapeutic uses of facet joint injections and provide level 1 evidence for their role. Future studies must look at short- and long-term pain relief, the benefit to quality of life of patients undergoing the therapy, the opportunities for rehabilitation during any potential windows of pain relief offered and the financial implications of the procedure. An attempt must be made to standardize or limit the influence of confounding variables during periods of long term follow-up (e.g. alternative analgesia, physiotherapy and exercise). Thus, a cost-risk-benefit ratio 
may be attained and an assessment made of the potential therapeutic use of facet joint injections. Only when the results of such well-designed randomized controlled trials are available can we be sure that the injection of facet joints in the treatment of lower back pain is clinically and financially justifiable.

Saket Tibrewal, Osman H Khan and Sheo B Tibrewal

Emails: sak11@hotmail.com, osmanhkhan@yahoo.com and sb.tibrewal@virgin.net

\section{REFERENCES}

1 Ghormley RK. Low back pain with special reference to the articular facets, with presentation of an operative procedure. JAMA 1933;101:773

2 Hirsch C, Ingelmark B-E, Miller M. The anatomical basis for low back pain. Acta Othop Scand 1963;33:1

3 Mooney V, Robertson J. The facet syndrome. Clin Orthop 1976;115:149

4 Glover JR. Arthrography of the joints of the lumbar vertebral arches. Orthop Clin North Am 1997;8:37-42

5 Moran R, O'Connell D, Walsh MG. The diagnostic value of facet joint injections. Spine 1988; 13:1407

6 Dory MA. Arthrography of the lumbar facet joints. Radiology 1981;140:23-7

7 Eisenstein SM, Parry CR. The lumbar facet arthrosis syndrome.J Bone Joint Surg 1987;69B:3
8 Jackson RP, Jacobs RR, Montesano PX. Facet joint injection in low back pain. A prospective statistical study. Spine 1988;13:966

9 Bogduk N: International spinal injection society guidelines for the performance of spinal injection procedures. Part 1. Zygoapophysial joint blocks. Clin J Pain 1997;13:285-302

10 Schwarzer AC, Wang SC, O'Driscoll D, et al. The ability of computed tomography to identify a painful zygapophysial joint in patients with chronic low back pain. Spine 1995;20:907-12

11 Pneumaticos SG, Chatziioannou SN, Hipp JA, Moore WH, Esses SI. Low back pain: prediction of short-term outcome of facet joint injection with bone scintigraphy. Radiology 2006;238:693-8

12 Fairbank JCT, Park WM, McCall IW, O'Brien JP. Apophysial injection of local anaesthetic as a diagnostic aid in primary low back pain syndromes. Spine 1981;6:598-605

13 Holm I, Friis A, Ivar Brox J, Gunderson R, Steen H. Minimal influence of facet joint anaesthesia on isokinetic muscle performance in patients with chronic degenerative low back disorders. Spine 2000;25:2091-4

14 Slipman CW, Bhat AL, Gilchrist RV, Issac Z, Chou L, Lenrow DA. A critical review of the evidence for the use of zygapophysial injections and radiofrequency denervation in the treatment of low back pain. Spine J 2003;3:310-6

15 van Tulder MW, Koes B, Seitsalo S, Malmivaara A. Outcome of invasive treatment modalities on back pain and sciatica: an evidencebased review. Eur Spine J 2006;15(Suppl 1):S82-S92.

16 Boswell MV, Colson JD, Sehgal N, Dunbar EE, Epter R. A systematic review of therapeutic facet joint interventions in chronic spinal pain. Pain Physician 2007;10:229-53

17 Carette S, Marcoux S, Truchon R, et al. A controlled trial of corticosteroid injections into facet joints for chronic low back pain. $N$ Engl J Med 1991;325:1002-7

\section{International Journal of STD \& AIDS Clinical Practice in Sexual Health Official journal of BASHH and IUSTI}

If you are involved in researching and treating sexually transmissible infections, HIV and AIDS, then the International Journal of STD and AIDS is the journal for you.

This peer-reviewed monthly journal contains in-depth editorial reviews, original articles and research, short papers, case reports, audit reports and CPD papers. There is also a lively correspondence column, a book review section, and news from the genitourinary medicine associations. Occasional supplements are also published and are supplied free to subscribers.

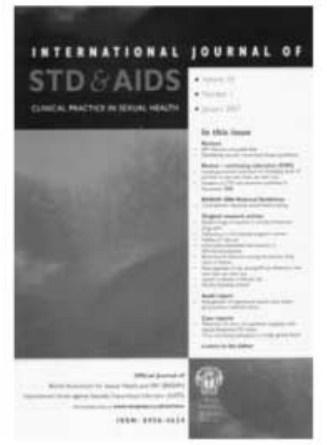

TO FIND OUT FURTHER INFORMATION OR TO VIEW A FREE SAMPLE ISSUE VISIT www.rsmpress.co.uk/std.htm 